\title{
Rates and factors associated with falls in older European Americans, Afro-Caribbeans, African- Americans, and Hispanics
}

This article was published in the following Dove Press journal:

Clinical Interventions in Aging

23 October 2015

Number of times this article has been viewed

\author{
Edgar Ramos Vieira ${ }^{1,2}$ \\ Ruth Tappen ${ }^{3}$ \\ Gabriella Engstrom ${ }^{3}$ \\ Bruno R da Costa' \\ 'Department of Physical Therapy, \\ 2Department of Neuroscience, Florida \\ International University, Miami, FL, \\ USA ${ }^{3}$ Christine E. Lynn College of \\ Nursing, Florida Atlantic University, \\ Boca Raton, FL, USA
}

Purpose: To evaluate rates and factors associated with older adult falls in different ethnic groups.

Participants and methods: Information on demographics, medical and falls history, and pain and physical activity levels was collected from 550 community-dwelling older adults (75 \pm 9 years old, 222 European Americans, 109 Afro-Caribbeans, 106 African-Americans, and 113 Hispanics).

Results: Taking medications for anxiety (risk ratio $[R R]=1.4,95 \%$ confidence interval $[\mathrm{CI}]=1.1-2.0)$, having incontinence $(\mathrm{RR}=1.4,95 \% \mathrm{CI}=1.1-1.8, P=0.013)$, back pain $(\mathrm{RR}=1.4$, $95 \% \mathrm{CI}=1.0-1.8)$, feet swelling $(\mathrm{RR}=1.3,95 \% \mathrm{CI}=1.1-1.7)$, and age $\geq 75$ years $(\mathrm{RR}=1.3,95 \%$ $\mathrm{CI}=1.0-1.6)$ were associated with falls. The associations were stronger for Afro-Caribbeans, but they presented approximately $40 \%$ lower prevalence of falls than the other groups.

Conclusion: Taking anxiety medication, incontinence, back pain, feet swelling, and age $\geq 75$ years were associated with falls, and Afro-Caribbeans presented lower prevalence of falls. These findings need to be taken into consideration in clinical interventions in aging.

Keywords: ethnicity, falls, risks, community dwelling, older adults

\section{Introduction}

Falls (unplanned descents to the ground or lower level) are the most common cause of injury and death among older adults ( $\geq 65$ years old). ${ }^{1,2}$ One in three older adults fall, $25 \%$ of fallers require medical care (2.4 million in the USA in $2011,37.3$ million per year worldwide) and 424,000 people suffer fall-related deaths yearly. ${ }^{3}$ Every 15 seconds an older adult goes to an emergency and every 29 minutes an older adult dies due to a fall. ${ }^{4}$ In 2011 , Whites accounted for $89 \%$ of fall-related deaths $(14.7 / 100,000)$ and hospitalizations in Florida; Blacks for $4 \%$ and other non-Whites for $6 \% .{ }^{5}$ Estimates for fall-related medical costs by 2020 in the USA have been increased from 43.8 billion in 2004 to 54.9 billion in 2011, and to 67.7 billion in $2014 .^{6,7}$

Falls can also lead to fear of falling resulting in further functional decline and may lead to nursing home placement; $40 \%$ of nursing home admissions happen after a fall. ${ }^{8,9}$ Falls are responsible for $95 \%$ of the hip fractures and $70 \%$ of the older hip fracture patients are discharged to nursing homes..$^{10}$ The good news is that some fall prevention programs have been reported to be effective: the Tai Chi-based Moving for Better Balance program reduced falls by 55\%; the Stepping On program reduced falls by $35 \%$; and the Matter of Balance program resulted in $\$ 938$ decrease in medical costs/year/participant. ${ }^{11}$

Fall rates are likely to differ by ethnic group, but few studies have evaluated ethnic differences in the prevalence and risks for falls. ${ }^{12,13}$ The objective of this study was to 
evaluate the rates and factors associated with falls in older African-Americans, Afro-Caribbeans, Hispanic Americans, and European Americans. For the most part, this study evaluated variables already in the literature, but the breakdown and comparison among different ethnic groups is new and important to understand and be able to address the specific needs of older adults from these groups.

\section{Materials and methods Subjects}

We evaluated a convenience sample of ethnically diverse community-dwelling older adults residing in South Florida who volunteered to participate in the study. The participants were recruited using adds and by word of mouth at health fairs, senior centers, housing developments, and by referrals from other participants from 2012 to 2014. The inclusion criteria were: age $\geq 60$ years, walking independently or using an assistive device, age/education-adjusted Mini Mental State Examination score $\geq 23$, and self-reported to belong to one of the four ethnic groups studied (African-Americans, Afro-Caribbeans, Hispanic Americans, and European Americans). The sample included 550 community-dwelling South Floridians with mean (standard deviation [SD]) age of 75 (9) years. The Florida Atlantic University Institutional Review Board approved the study. Written informed consent was obtained from all patients.

\section{Data collection}

All instruments were translated into Spanish and Creole, and administered by bilingual speakers of English-Haitian Creole, or English-Spanish at the participants' home or at a community center. Given the inclusion criteria (age/education-adjusted Mini Mental State Examination score $\geq 23$ ), the participants had good cognitive status; therefore, they responded to the questions themselves. The questions were read for the participants and the research assistants filled in all answers. Falls were assessed using the question: "Have you fallen down in the last two years?" This is a standardized question from the Health and Retirement Study: http://hrsonline.isr.umich.edu/index.php. Characteristics previously found to be associated with falls in community-dwelling older adults were tabulated, including: age, sex, ethnicity, physical activity, feet swelling, difficulty remembering, difficulty shopping, ambulatory devices, fatigue, medications, shortness of breath, dizziness, back pain, and urinary incontinence. ${ }^{14}$ We used a limited dataset of questions and information on participant characteristics to minimize the effects of multiple testing when comparing between groups. The variables were selected based on the previous literature in this area and physiological plausibility for a relationship with falls.

\section{Statistical analysis}

Univariable and multivariable analyses of association between falls and the characteristics were conducted, and generalized linear models were used to derive risk ratios (RRs) and 95\% confidence intervals. ${ }^{15}$ Multiple imputations were used to create 20 imputed datasets to address missing covariate data points. ${ }^{16}$ To analyze the association between falls and age, we dichotomized those above and below the mean age of the sample ( 75 years) to compare their risk of falls. A multivariable analysis stratified by ethnicity was conducted for the significant $(P<0.05)$ fall covariates in the main analysis. All $P$-values are two-sided and the analyses were conducted using Stata (Stata Statistical Software 2013: Release 13. StataCorp LP, College Station, TX, USA).

\section{Results}

The mean (SD) age of the participants was 75 (9) years; $40 \%$ $(n=222)$ were European Americans, 21\% $(n=113)$ were Hispanics, 20\% $(n=109)$ were Afro-Caribbeans, and 19\% $(n=106)$ were African-Americans. Ninety-four percent of the AfricanAmericans, $78 \%$ of the European Americans, $6 \%$ of the Hispanics, and $19 \%$ of the Afro-Caribbeans were born in the USA. Moderate physical activity was performed at least once a week by $63 \%$ of the participants; fatigue-related dysfunction was reported by $59 \%$ and back pain by $45 \%$ (Table 1 ).

Table I Characteristics of participants

\begin{tabular}{ll}
\hline Characteristics & $\mathbf{N}=\mathbf{5 5 0 , \mathbf { n } ( \% )}$ \\
\hline Ethnicity & $106(19)$ \\
African-American & $109(20)$ \\
Afro-Caribbean & $113(21)$ \\
Hispanic & $222(40)$ \\
European American & $198(36)$ \\
Fallers & $75(9)$ \\
Age (mean, SD) & $157(29)$ \\
Males & $345(63)$ \\
Practice moderate physical activities & \\
at least once a week & $91(17)$ \\
Use of ambulatory device & $67(12)$ \\
Has difficulty remembering & $72(13)$ \\
Has difficulty shopping alone & $323(59)$ \\
Fatigue-related dysfunction & $55(10)$ \\
Use of anxiety medication & $144(26)$ \\
Use of arthritis medication & $65(12)$ \\
Use of depression medication & $149(27)$ \\
Persistent swelling of the feet & $98(18)$ \\
Shortness of breath while awake & $80(15)$ \\
Persistent dizziness or lightheadedness & $249(45)$ \\
Back pain & $157(29)$ \\
Urinary incontinence &
\end{tabular}

Abbreviation: SD, standard deviation. 
Table 2 presents characteristics and crude $\operatorname{RRs}(>1=>$ falls risk). Being male and practicing moderate physical activity at least once a week were the only characteristics not significantly associated with falls in the univariable analysis. Afro-Caribbeans were approximately $40 \%$ less likely to have fallen than the other groups $(P \leq 0.022)$. Participants were 1.5-1.9 times more likely to have fallen if they used anxiety medication, were incontinent, had back pain, fatiguerelated dysfunction, feet swelling, or difficulty remembering $(P \leq 0.004)$.

The multivariable fall RRs were smaller than the crude RRs (Figure 1). Age $\geq 75$ years, taking anxiety medication, feet swelling, back pain, and incontinence were significantly associated with falls in the multivariable analysis.

Table 3 shows the adjusted RRs stratified by ethnicity for these covariates; the trends were similar across ethnic groups, but the RRs were $5 \%$ to $12 \%$ higher for the Afro-Caribbeans than for the other groups.

\section{Discussion}

Afro-Caribbeans presented lower prevalence of falls. One potential explanation is that foreign-born immigrants tend to have lower rates of falls. ${ }^{12,17}$ While $78 \%$ of the European Americans and $94 \%$ of the African-Americans were born in the USA, only $19 \%$ of the Afro-Caribbeans and $6 \%$ of the Hispanics were born in the USA. However, the lower rate of falls among Afro-Caribbeans compared to Hispanics still cannot be explained by the reason of being born abroad.
The factors contributing to lower prevalence of falls among Afro-Caribbeans need further investigation. This finding indicates that using the falls prevalence data among the general population is not appropriate to assess how AfroCaribbeans are doing in relation to falls. Falls prevalence from the specific ethnic group of the participants should be used instead.

Taking anxiety medication, incontinence, back pain, feet swelling, and age $\geq 75$ years were associated with falls in the multivariable model. Age is a nonmodifiable risk factor, but addressing the underling health issues may help reduce falls risk. The relationship between taking anxiety medication and falls may be explained by the medication side effects and/or by anxiety itself. ${ }^{18}$ Community-dwelling older adults taking psychotropic medications were found to have 1.5-3.7 higher odds of falls than those not taking it. ${ }^{19,20}$ Medication review and reconciliation may help reduce the risk of falls among these patients. Also, anxious subjects are likely to present more fear of falls, which increase the risk due to activity restriction and deconditioning. ${ }^{8}$

As in this study, urinary incontinence among racially diverse cohort of older adults has been found to be related to falls. ${ }^{21}$ This relationship is likely related to the need to rush to the toilet possibly resulting in inattention to environmental hazards (eg, carpet edges, cords, wet floors). The increased risk associated with urinary incontinence may be reduced by treating the symptoms as well as by making sure that the path between the person with incontinence bed and bathroom is

Table 2 Characteristics of participants according to fall event: univariable analysis

\begin{tabular}{|c|c|c|c|c|}
\hline \multirow[t]{2}{*}{ Characteristics } & \multirow{2}{*}{$\frac{\text { Fall, } n=198}{n(\%)}$} & \multirow{2}{*}{$\frac{\text { No fall, } n=352}{n(\%)}$} & \multirow{2}{*}{$\frac{\text { Crude risk ratio }}{\operatorname{RR}(95 \% \mathrm{Cl})}$} & \multirow[t]{2}{*}{$P$-value } \\
\hline & & & & \\
\hline \multicolumn{5}{|l|}{ Ethnicity } \\
\hline Afro-Caribbean & $26(24)$ & $83(76)$ & 1.00 & - \\
\hline African-American & $42(40)$ & $64(60)$ & $1.63(1.07-2.47)$ & 0.022 \\
\hline Hispanic & $44(39)$ & $69(6 I)$ & $1.62(1.07-2.44)$ & 0.022 \\
\hline European American & $86(39)$ & $136(61)$ & $1.57(1.08-2.29)$ & 0.019 \\
\hline Male sex & $53(34)$ & $104(66)$ & $0.91(0.70-1.17)$ & 0.461 \\
\hline Practice physical activities at least once a week & $132(38)$ & $213(62)$ & $1.17(0.92-1.49)$ & 0.207 \\
\hline Age $\geq 75$ years & $111(43)$ & $150(57)$ & $1.37(1.09-1.72)$ & 0.007 \\
\hline Use of ambulatory device & $44(48)$ & $47(52)$ & $1.43(1.11-1.85)$ & 0.006 \\
\hline Has difficulty shopping alone & $37(5 \mathrm{I})$ & $35(49)$ & $1.46(1.11-1.93)$ & 0.007 \\
\hline Has difficulty remembering & $35(52)$ & $32(48)$ & $1.50(1.14-1.99)$ & 0.004 \\
\hline Fatigue-related dysfunction & $137(42)$ & $186(58)$ & $1.58(1.21-2.06)$ & 0.001 \\
\hline Use of anxiety medication & $35(64)$ & $20(36)$ & $1.86(I .43-2.4 I)$ & $<0.001$ \\
\hline Use of arthritis medication & $68(47)$ & $76(53)$ & $1.43(1.10-1.84)$ & 0.007 \\
\hline Use of depression medication & $33(5 \mathrm{I})$ & $32(49)$ & $1.44(1.07-1.95)$ & 0.018 \\
\hline Persistent swelling of the feet & $71(48)$ & $78(52)$ & $1.52(1.21-1.91)$ & $<0.001$ \\
\hline Shortness of breath while awake & $47(48)$ & $51(52)$ & $1.43(1.11-1.84)$ & 0.005 \\
\hline Persistent dizziness or lightheadedness & $37(46)$ & $43(54)$ & $1.39(1.06-1.82)$ & 0.017 \\
\hline Back pain & $116(47)$ & $133(53)$ & $1.68(1.33-2.13)$ & $<0.001$ \\
\hline Urinary incontinence & $84(54)$ & $73(46)$ & $1.84(1.48-2.29)$ & $<0.001$ \\
\hline
\end{tabular}

Abbreviation: $\mathrm{Cl}$, confidence interval. 


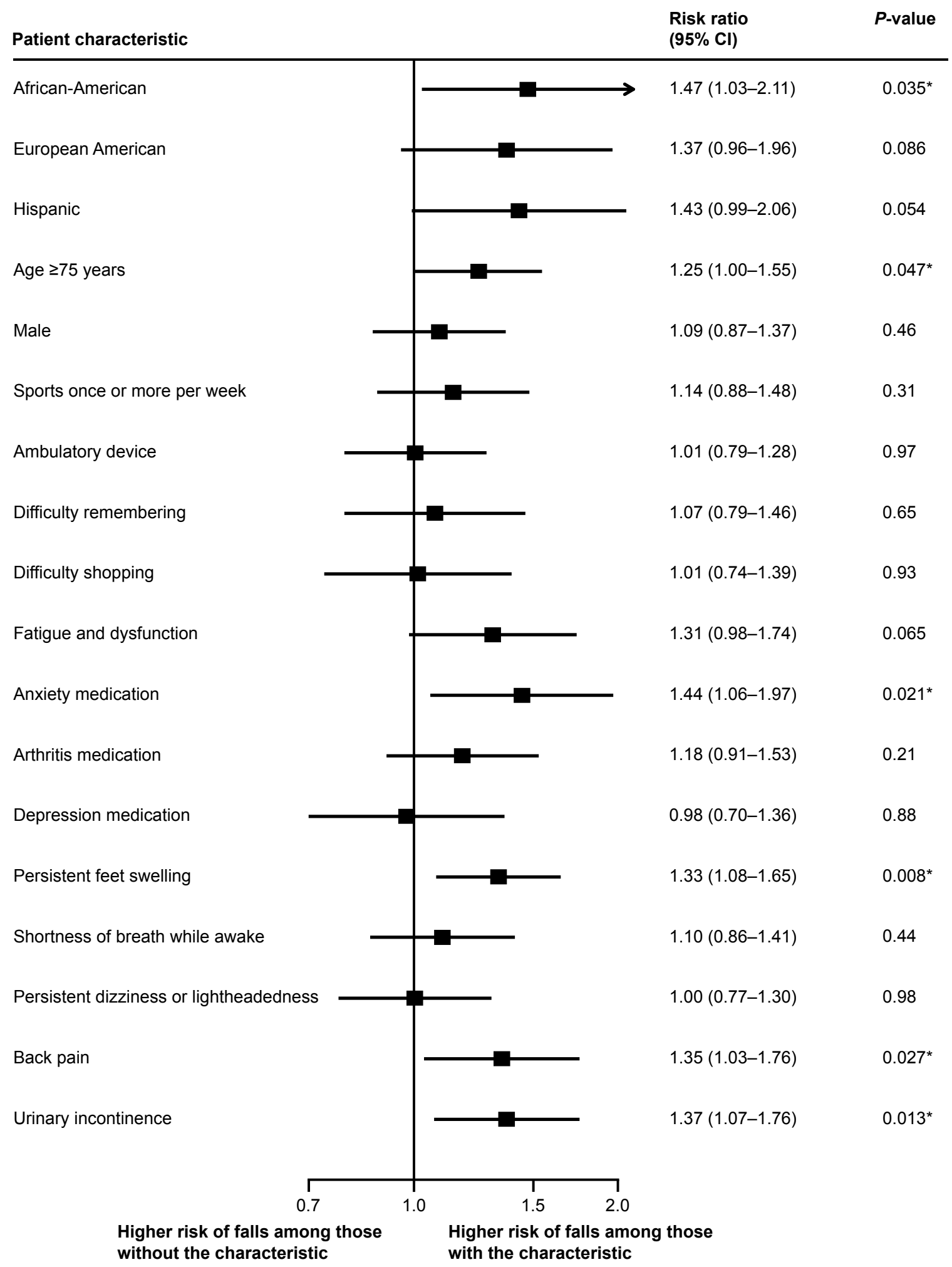

Figure I Multivariable analysis of factors associated with falls. Note: $* P<0.05$.

clear of clutter, furniture, and cords; that the floors are not wet; that the person wears proper anti-slip footwear or socks; and that bathroom night-lights are installed.

Back pain may increase the risk of falls because it affects balance and mobility. ${ }^{22}$ Low back pain has been found to be independently associated with falls, and a back exercise program reduced falls in older women. ${ }^{23,24}$ Therefore, interventions to reduce back pain, such as physical therapy, exercises, and weight loss, may also reduce falls risk. The relationship between feet swelling and falls is likely to be due to decreased 
Table 3 Fall risk ratio (95\% confidence interval $[\mathrm{Cl}])$ stratified according to ethnicity for the characteristics significantly associated with falls in the multivariable model

\begin{tabular}{|c|c|c|c|c|}
\hline \multirow[t]{2}{*}{ Characteristics } & Afro-Caribbean & African-American & Hispanic & European American \\
\hline & $n=109(95 \% \mathrm{Cl})$ & $n=106(95 \% \mathrm{Cl})$ & $n=I \mid 3(95 \% C l)$ & $\mathrm{n}=222(95 \% \mathrm{Cl})$ \\
\hline Age $\geq 75$ years & I.34 (I.04-I.74) & $\mathrm{I} .28$ (I.04-I.57) & $1.26(1.04-1.52)$ & I.25 (I.04-I.50) \\
\hline Persistent feet swelling & $1.42(1.07-1.90)$ & $\mathrm{I} .32(\mathrm{I} .08-\mathrm{I} .6 \mathrm{I})$ & I.3I (I.07-I.62) & $1.32(1.06-1.64)$ \\
\hline Back pain & 1.43 (I.08-1.89) & 1.33 (I.08-1.63) & 1.32 (I.08-I.63) & $1.32(1.08-1.61)$ \\
\hline Anxiety medication & $1.64(1.05-2.56)$ & $1.49(1.07-2.06)$ & 1.47 (1.07-2.03) & 1.46 (I.07-I.99) \\
\hline Urinary incontinence & 1.65 (1.19-2.27) & 1.50 (I.I8-I.89) & 1.48 (I.18-I.86) & 1.46 (I.I8-I.82) \\
\hline
\end{tabular}

proprioception as a result of the compression of the neurovascular structures. Proprioception is the ability to detect joint motion and position, and it depends on mechano-sensory receptors on the joints, ligaments, tendons, and muscles. Vision and proprioception interact with the vestibular system and provide the central nervous system with information on the position of body allowing for postural control and balance maintenance. ${ }^{25}$ When the information sent from the sensory systems is unpredictable, insufficient, or conflicting there is loss of balance and inability to recover from disturbances. ${ }^{26}$ Similarly to back pain and incontinence, addressing the causes and consequences of feet swelling may reduce the risk of falls.

Health conditions had a stronger role on falls than age alone. However, older age may be related to falls due to aging-related physiological and functional decline. Gait impairments in older adults are related to declines in balance, muscle strength, and range of motion. ${ }^{27}$ However, practicing moderate physical activity at least once a week was not associated with falls. The health benefits of physical activity are well established. ${ }^{28}$ What may help explain our finding is that the physical activity intensity and frequency is important and "practicing moderate physical activity at least once a week" may be insufficient to reduce the risk of falls. Further studies should investigate the dose-response relationship between exercise practice and falls rates. One of the limitations of the current study is that we did not include physical measures. Studies using physical measures to compare between these ethnic groups are needed. Another limitation of our study is that the sample was not randomly selected and therefore it may not represent the general population. This is a common limitation of studies conducted in the community where randomization is rarely feasible.

\section{Conclusion}

Taking anxiety medication, incontinence, back pain, persistent swelling of the feet, and age $\geq 75$ years were significantly associated with falls after adjusting for confounders. The strength of association was higher for Afro-Caribbeans, but this group presented lower prevalence of falls than African-Americans, Hispanics, and European Americans.
These findings need to be taken into consideration in clinical interventions in aging.

\section{Acknowledgments}

This study was funded by the Florida Atlantic University Research Retirement Foundation (Grant \#2012-283, PI: Tappen R). The study sponsors did not participate in the design, methods, subject recruitment, data collection, analysis, or preparation of the article.

\section{Disclosure}

The authors report no conflicts of interest in this work.

\section{References}

1. Stevens JA, Mack KA, Paulozzi LJ, Ballesteros MF. Self-reported falls and fall-related injuries among persons aged $\geq 65$ years - United States, 2006. J Safety Res. 2008;39(3):345-349.

2. World Health Organization. Fact sheet 344: falls. 2012. Available from: http://www.who.int/mediacentre/factsheets/fs344/en/. Accessed June 06, 2015.

3. Sterling DA, O'Connor JA, Bonadies J. Geriatric falls: injury severity is high and disproportionate to mechanism. J Trauma. 2001;50(1): 116-119.

4. Bedlin H. It's Older Americans Month: Are Our Seniors Safe?. Ann Arbor: Altarum Institute; 2014. Available from: http://altarum.org/ health-policy-blog/it $\%$ E2\%80\%99s-older-americans-month-are-ourseniors-safe. Accessed 02/12, 2015.

5. Florida Department of Health. Florida Injury Facts, Hip Fractures (Ages 65+). Tallahassee, FL: Florida Department of Health; 2012. Available from: http://www.floridahealth.gov/statistics-and-data/ florida-injury-surveillance-system/_documents/data-fact-sheets/hipfx-2012.pdf. Accessed 06/15, 2015.

6. Englander F, Hodson TJ, Terregrossa RA. Economic dimensions of slip and fall injuries. J Forensic Sci. 1996;41(5):733-746.

7. Centers for Disease Control and Prevention (CDC). Costs of Falls among Older Adults. Atlanta GA: Centers for Disease Control and Prevention. Available from: http://www.cdc.gov/HomeandRecreationalSafety/ Falls/fallcost.html. Accessed 6/24, 2015.

8. Deshpande N, Metter EJ, Lauretani F, Bandinelli S, Guralnik J, Ferrucci L. Activity restriction induced by fear of falling and objective and subjective measures of physical function: a prospective cohort study. J Am Geriatr Soc. 2008;56(4):615-620. doi:10.1111/j.1532-5415.2007.01639.x.

9. Spoelstra SL, Given B, You M, Given CW. The contribution falls have to increasing risk of nursing home placement in communitydwelling older adults. Clin Nurs Res. 2012;21(1):24-42. doi:10.1177/ 1054773811431491.

10. Scott V, Wagar L, Elliott S. Falls \& related injuries among older Canadians: Fall-related hospitalizations \& intervention initiatives. Victoria, BC: Victoria Scott Consulting; 2010. 
11. Centers for Medicare \& Medicaid Services. Report to Congress: The Centers for Medicare \& Medicaid Services' Evaluation of CommunityBased Wellness and Prevention Programs Under Section 4202 (b) of the Affordable Care Act. Baltimore: Centers for Medicare \& Medicaid Services; 2013.

12. Han BH, Ferris R, Blaum C. Exploring ethnic and racial differences in falls among older adults. J Community Health. 2014;39(6):1241-1247. doi:10.1007/s10900-014-9852-8.

13. Nicklett EJ, Taylor RJ. Racial/Ethnic predictors of falls among older adults: the health and retirement study. J Aging Health. 2014;26(6): 1060-1075. doi:10.1177/0898264314541698.

14. Deandrea S, Lucenteforte E, Bravi F, Foschi R, La Vecchia C, Negri E. Risk factors for falls in community-dwelling older people: a systematic review and meta-analysis. Epidemiology. 2010;21(5):658-668. doi:10.1097/EDE.0b013e3181e89905.

15. Cummings P. Methods for estimating adjusted risk ratios. Stata J. 2009;9(2):175.

16. Sterne JA, White IR, Carlin JB, et al. Multiple imputation for missing data in epidemiological and clinical research: potential and pitfalls. BMJ. 2009;338:b2393. doi:10.1136/bmj.b2393.

17. Stanaway FF, Cumming RG, Naganathan V, et al. Ethnicity and falls in older men: low rate of falls in Italian-born men in Australia. Age Ageing. 2011;40(5):595-601. doi:10.1093/ageing/afr067.

18. Kerman M, Mulvihill M. The role of medication in falls among the elderly in a long-term care facility. Mt Sinai J Med. 1990;57(6):343-347.

19. Cumming RG, Miller JP, Kelsey JL, et al. Medications and multiple falls in elderly people: the St Louis OASIS study. Age Ageing. 1991;20(6): 455-461. doi:10.1093/ageing/20.6.455.

20. Landi F, Onder G, Cesari M, et al. Psychotropic medications and risk for falls among community-dwelling frail older people: an observational study. J Gerontol Biol Sci Med Sci. 2005;60(5):622-626. doi:10.1093/ gerona/60.5.622.
21. Vaughan CP, Brown CJ, Goode PS, Burgio KL, Allman RM, Johnson I. The association of nocturia with incident falls in an elderly communitydwelling cohort. Int J Clin Pract. 2010;64(5):577-583.

22. Champagne A, Prince F, Bouffard V, Lafond D. Balance, Falls-related self-efficacy, and psychological factors amongst older women with chronic low back pain: a preliminary case-control study. Rehabil Res Pract. 2012;2012:430374. doi:10.1155/2012/430374.

23. Muraki S, Akune T, Oka H, et al. Prevalence of falls and the association with knee osteoarthritis and lumbar spondylosis as well as knee and lower back pain in Japanese men and women. Arthritis Care Res (Hoboken). 2011;63(10):1425-1431. doi:10.1002/acr.20562.

24. Sinaki M, Brey RH, Hughes CA, Larson DR, Kaufman KR. Significant reduction in risk of falls and back pain in osteoporotic-kyphotic women through a Spinal Proprioceptive Extension Exercise Dynamic (SPEED) program. Mayo Clin Proc. 2005;80(7):849-855. doi:S00256196(11)61558-9

25. Weinstein BE. Geriatric audiology. Stuttgart: Thieme Medical Publishers; 2000.

26. Desmond AL. Vestibular function: clinical and practice management. Stuttgart: Thieme Medical Publishers; 2011.

27. Grabiner PC, Biswas ST, Grabiner MD. Age-related changes in spatial and temporal gait variables. Arch Phys Med Rehabil. 2001;82(1): 31-35.

28. Gardner MM, Robertson MC, Campbell AJ. Exercise in preventing falls and fall related injuries in older people: a review of randomised controlled trials. Br J Sports Med. 2000;34(1):7-17.
Clinical Interventions in Aging

\section{Publish your work in this journal}

Clinical Interventions in Aging is an international, peer-reviewed journal focusing on evidence-based reports on the value or lack thereof of treatments intended to prevent or delay the onset of maladaptive correlates of aging in human beings. This journal is indexed on PubMed Central, MedLine,

\section{Dovepress}

CAS, Scopus and the Elsevier Bibliographic databases. The manuscript management system is completely online and includes a very quick and fair peer-review system, which is all easy to use. Visit http://www.dovepress. com/testimonials.php to read real quotes from published authors. 